\title{
Thermal Decomposition Kinetics and Mechanism of In-Situ Prepared Bio-Based Poly(propylene 2,5-furan dicarboxylate)/Graphene Nanocomposites
}

\author{
Zoi Terzopoulou ${ }^{1}$, Evangelia Tarani ${ }^{2}$, Nejib Kasmi ${ }^{1}$, ${ }^{1}$ Lazaros Papadopoulos ${ }^{1}(\mathbb{D}$, \\ Konstantinos Chrissafis ${ }^{2, *}$, Dimitrios G. Papageorgiou ${ }^{3} \mathbb{B}$, George Z. Papageorgiou ${ }^{4}(\mathbb{D}$ and \\ Dimitrios N. Bikiaris $1, *$ (D) \\ 1 Laboratory of Polymer Chemistry and Technology, Department of Chemistry, \\ Aristotle University of Thessaloniki, GR54124 Thessaloniki, Greece; terzoe@gmail.com (Z.T.); \\ nejibkasmi@gmail.com (N.K.); lazaros.geo.papadopoulos@gmail.com (L.P.) \\ 2 Solid State Physics Department, School of Physics, Aristotle University of Thessaloniki, \\ GR54124 Thessaloniki, Greece; etarani@physics.auth.gr \\ 3 School of Materials and National Graphene Institute, University of Manchester, Oxford Road, \\ Manchester M13 9PL, UK; dimitrios.papageorgiou@manchester.ac.uk \\ 4 Chemistry Department, University of Ioannina, P.O. Box 1186, 45110 Ioannina, Greece; gzpap@uoi.gr \\ * Correspondence: hrisafis@physics.auth.gr (K.C.); dbic@chem.auth.gr (D.N.B.); \\ Tel.: +30-2310-99-8188 (K.C.); +30-2310-99-7812 (D.N.B.)
}

Received: 4 April 2019; Accepted: 1 May 2019; Published: 2 May 2019

\begin{abstract}
Bio-based polyesters are a new class of materials that are expected to replace their fossil-based homologues in the near future. In this work, poly (propylene 2,5-furandicarboxylate) (PPF) nanocomposites with graphene nanoplatelets were prepared via the in-situ melt polycondensation method. The chemical structure of the resulting polymers was confirmed by ${ }^{1} \mathrm{H}-\mathrm{NMR}$ spectroscopy. Thermal stability, decomposition kinetics and the decomposition mechanism of the PPF nanocomposites were studied in detail. According to thermogravimetric analysis results, graphene nanoplatelets did not affect the thermal stability of PPF at levels of $0.5,1.0$ and $2.5 \mathrm{wt} . \%$, but caused a slight increase in the activation energy values. Pyrolysis combined with gas chromatography and mass spectroscopy revealed that the decomposition mechanism of the polymer was not altered by the presence of graphene nanoplatelets but the extent of secondary homolytic degradation reactions was increased.
\end{abstract}

Keywords: poly(propylene 2,5 furandicarboxylate); graphene nanoplatelets; nanocomposites; bio-based polymers; thermal stability; decomposition mechanism

\section{Introduction}

In recent years, polymers have become a necessary part of modern life [1]. From clothes to housing, transportation to medicine and electronics, polymeric materials promote, foster and enable a sustainable society [2]. Environmental concerns have arisen though, mainly because the vast majority of these polymers is produced from non-renewable resources $[3,4]$, so a growing interest towards the preparation of materials and chemicals from renewable resources is observed [2,5-8]. Economic reasons, such as the fluctuation of crude oil prices since fossil fuel resources have been diminishing, along with environmental ones, such as the limited biodegradability and the significant greenhouse gas emissions from the production of fossil-based materials, have shifted the attention towards bio-based raw materials and polymers [6,9-11]. For renewable polymers to enter the marketplace, they must outperform the traditional ones both in price and in performance. To accomplish this, new routes for biomass conversion and monomer generation must be used, to discover new, high performance 
materials [1]. Renewable raw materials such as cellulose, lignin, proteins, starch and vegetable oils have been intensively explored in order to develop a sustainable bio-based economy [12,13] and their use has been promoted legislatively, both in U.S.A. and Europe [6,14]. In parallel, research towards discovering new materials is constant, as shown by numerous papers where plants [15] or bacteria [16] have been used to produce materials suitable for applications as waste water treatment and drug delivery.

One of the most important biomass derived monomers is 2,5 furandicarboxylic acid (FDCA). FDCA can be formed by oxidative dehydration of glucose or by oxidation of 5-hydroxy-methylfurfural, and is considered a bio-derived homologue of terephthalic acid (TPA) [17,18], a monomer widely used for the production of commodity plastics such as poly(ethylene terephthalate) (PET), poly(propylene terephthalate) (PPT) and poly(butylene terephthalate) (PBT) that find many applications in today's society. In fact, FDCA is a monomer of such importance, that it has been included in the US Department of Energy list of top priority bio-based chemicals, which was published in 2004 [17]. Since that, polyesters containing furan moieties in their structure have been widely investigated, bearing promising results compared to their fossil-based counterparts [19-24]. The combination of FDCA with bio-based diols leads to fully bio-based polyesters that are already being produced on an industrial scale. Among them, poly(ethylene 2,5 furandicarboxylate) (PEF) has attracted the greatest interest, as it considered a viable alternative to PET for packaging applications, thus many parameters of its synthesis have been examined thoroughly in recent years [25-28].

Aside from PEF, many polyesters based on FDCA have been synthesized using various diols [21,29-31], one of them being 1,3-propanediol (PDO). Polyesters derived from PDO were not studied till recently, due to unavailability of the specific monomer in large quantities [32]. With the development of new processes of production though, the situation has changed and there has been increased interest towards this family of polyesters [33,34]. Poly(propylene terephthalate) (PPT) was the first polymer of this category that was available in the market [35]. Its applications were mainly the production of fibers, hence the odd number of methylene groups in the diol's structure provide better resilience and stress recovery properties compared with other terephthalic homologues from diols with an even number of methylene groups [36]. Poly(propylene furanoate) (PPF) is the bio-based counterpart of PPT. Industrially, PPF is a polyester that is used in packaging applications like multilayered materials, since it has good gas barrier properties [37,38].

The necessity to improve the produced materials has led to the use of various types of fillers as means to enhance the final product's performance. While traditional composite materials contain a big quantity of fillers bound to the polymer matrix, in nanocomposites small quantities of fillers can result in significant changes of the polymer properties, due to the enormous surface area per unit volume of the nanofillers, among other factors. Carbon nanofillers especially, ones like carbon nanotubes, graphene, and graphene oxide have been proposed as next-generation multifunctional nanofillers for the improvement of the thermal, electrical and mechanical properties of diverse matrices [39,40]. In recent publications, several types of carbon nanofillers were used enhance the properties of polymeric matrices. For example, carbon black was introduced to polyurethane polymers and it resulted in improved mechanical properties, while also increasing the wear resistance of the resulting materials [41]. The mechanical properties of polymeric materials are also enhanced by the addition of carbon fibers, especially resins. Due to their prominent strength-weight and stiffness-weight ratios, carbon fibers are excellent reinforcements for resin composites [42], and drawbacks such as poor interfacial interactions with the polymer matrix can be overcome by surface modification, resulting in materials with improved mechanical properties $[43,44]$. The addition of carbon nanofillers also results in materials with improved electrical properties, as shown in recent papers. For instance, graphene oxide was used to create supercapacitors that display excellent cycle stability even after 500 cycles [45]. Also, graphene sheets were found to enhance the conductivity of carbon-sulfur membranes and increasing their long term cycling stability [46]. Graphene, one of the more interesting substances in the fields of materials science, physics, chemistry, and nanotechnology, is a free-standing 2D crystal with one-atom thickness [47]. As an allotrope of carbon comprises layers of six-atom rings in a honeycombed network and can be 
wrapped to generate $0 \mathrm{D}$ fullerenes, rolled up to form $1 \mathrm{D}$ carbon nanotubes, and stacked to produce 3D graphite [48]. More recently, developments have been made towards the preparation of thinner forms of graphite, known as graphene nanoplatelets (GNPs). All types of graphitic material are covered by the definition of GNPs, from $100 \mathrm{~nm}$ thick platelets down to single layer graphene [49]. It is, however, the availability of single- or few-layer graphene that has caused the most excitement in recent times [50]. The addition of GNPs to polymers has been found to lead to substantial improvements in the thermal, mechanical and electrical properties at lower loadings than are needed with expanded graphite because of high intrinsic thermal conductivity, large specific surface area, and high two-dimensional sheet geometry [51-58].

Different types of fillers have been used for the improvement of the properties of furan-based polyesters, including nanoclays [23,57], nanocellulose [59-61], nanosized silica and titanium dioxide [28], graphene [62], graphene oxide and multi wall carbon nanotubes [63]. Recently, Paszkiewicz et al. [62] prepared PPF nanocomposites with low concentrations (0.1 and $0.3 \mathrm{wt} . \%)$ of few-layer graphene, and found that the addition of the filler did not change the glass transition temperature or the melting behavior of the polymer, but resulted in inhibition of the transport of oxygen molecules into and through the material. However, there is no information published about the effect of GNPs on the thermal degradation behavior and decomposition mechanism of PPF nanocomposites in the literature. Thermal stability of polymers and their nanocomposites is a crucial parameter that affects their thermal processing and their final applications.

In this work, neat PPF and PPF/GNP nanocomposites containing 0.5, 1, and $2.5 \mathrm{wt} . \%$ GNPs were synthesized in-situ by melt polycondensation. Then, the chemical structure of the resulting polymers was studied by ${ }^{1} \mathrm{H}-\mathrm{NMR}$ spectroscopy. The effect of GNPs content on the thermal stability and thermal degradation of these polyesters along with a decomposition kinetics study was performed using thermogravimetric analysis (TGA), in order to reveal similarities and differences on their decomposition mechanism. Furthermore, pyrolysis-gas chromatography/mass spectroscopy (Py-GC/MS) was employed on the PPF/GNP nanocomposites in order to identify the individual fragments from each sample and obtain structural information concerning the decomposition mechanism.

\section{Results and Discussion}

\subsection{Synthesis and Molecular Characterization}

The PPF nanocomposites were synthesized via the two-step melt polycondensation method. The reaction procedure is presented in Scheme 1. The obtained nanocomposites were black solids.

Stage 1: Transesterificatiom
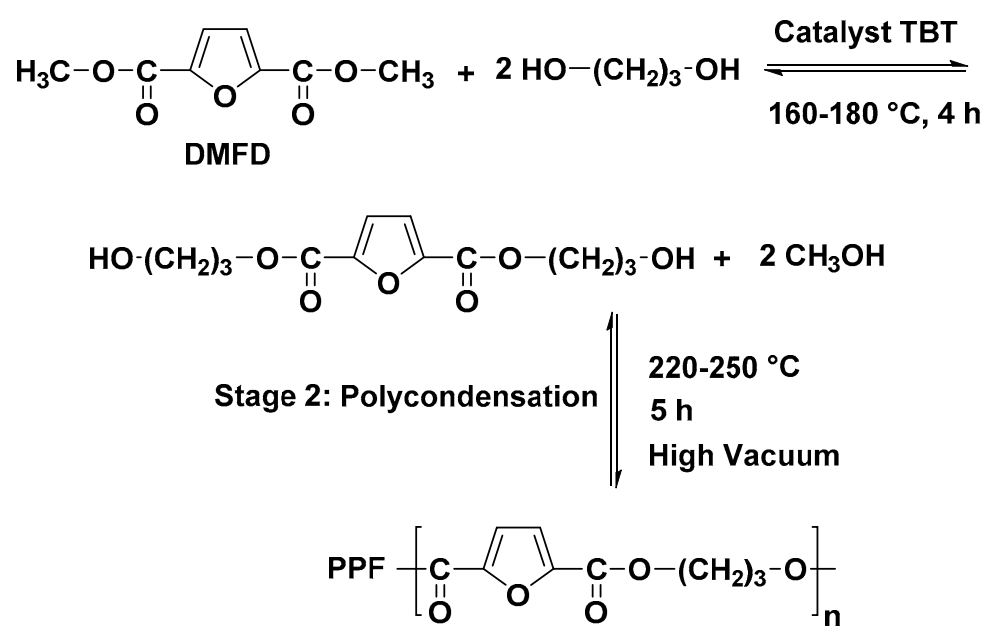

Scheme 1. Synthesis of PPF. 
The intrinsic viscosity values of PPF and PPF/GNP nanocomposites with 0.5, 1, 2.5 wt.\% GNPs were $0.62,0.51,0.5$ and 0.57 , respectively. The structure of the prepared materials was verified by ${ }^{1} \mathrm{H}-\mathrm{NMR}$ spectroscopy, presented in Figure 1, along with the peak assignments. In the spectrum of neat $\mathrm{PPF}$, the propylene glycol protons appear at lower values, at $4.75 \mathrm{ppm}$ for the protons near the oxygen atoms (b) which are the most deprotected, and at $2.44 \mathrm{ppm}$ for the (c) protons. As for the furan ring protons (a), they are the most deprotected, due to the $\pi$ electron system of the ring and the carbonyl groups, and they appear at $7.45 \mathrm{ppm}$. The above results are in accordance with our previous work [23]. The same peaks were recorded for the nanocomposites thus confirming that the addition of GNPs had no effect on the molecular structure of the prepared polyesters.

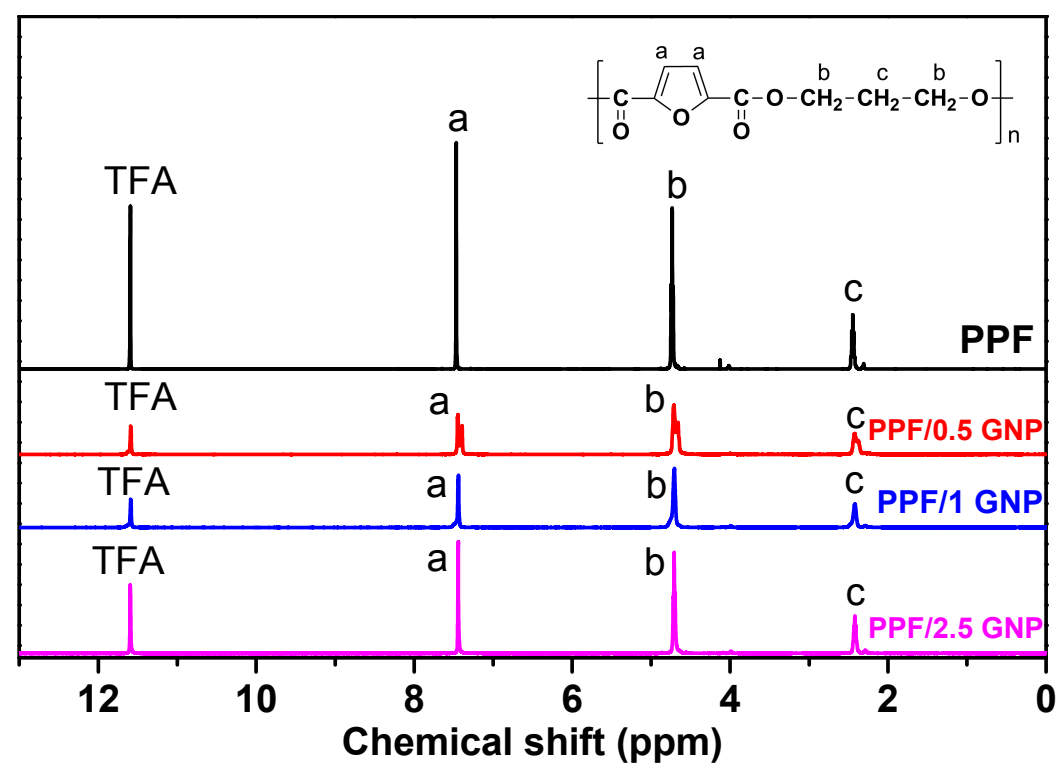

Figure 1. PPF structure, ${ }^{1} \mathrm{H}-\mathrm{NMR}$ spectra and peak assignments of PPF and PPF/GNP nanocomposites.

The crystalline structure of the materials was assessed with WAXD analysis. As seen in the diffractograms of Figure 2, PPF and PPF/GNP nanocomposites were found to be amorphous, as they present a broad peak at $2 \theta=22^{\circ}$. In the second diffractogram (Figure $2 b$ ) it is observed that the GNPs present a peak at $2 \theta=26.5^{\circ}$, with $\mathrm{d}=3.35 \AA$. In the nanocomposite materials, the same peak can be seen in all three polymers, and its intensity is increasing by increasing the loading of the material with the nanofiller, evidence of an intercalated polymer/GNPs structure. Similar results were shown in other studies examining graphene nanocomposites [64,65].

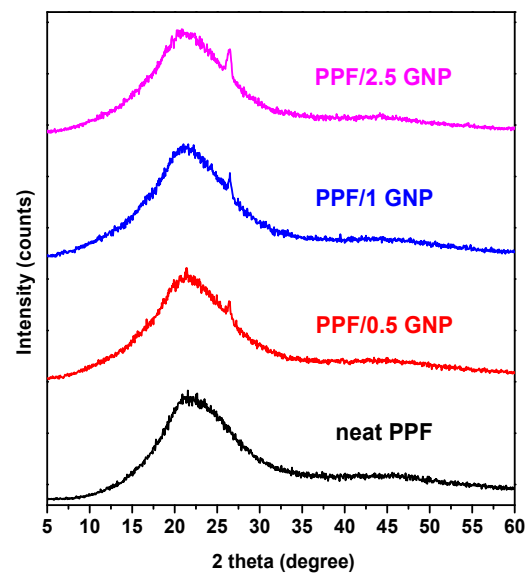

(a)

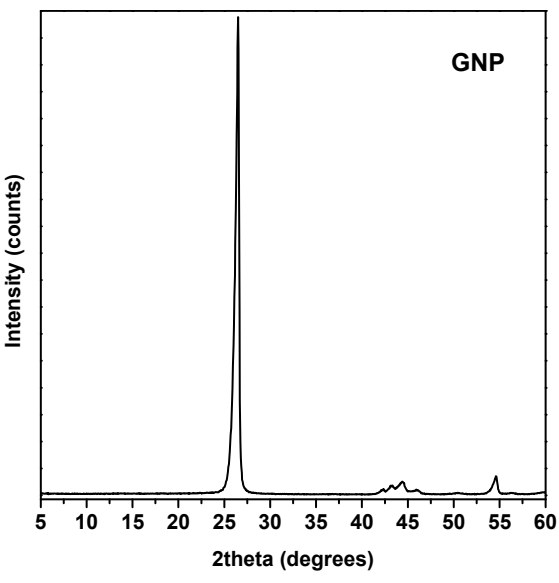

(b)

Figure 2. X-ray diffraction patterns of (a) PPF/GNP nanocomposites; (b) GNP. 


\subsection{Thermal Stability of PPF/GNP Nanocomposites}

Thermogravimetric analysis (TGA) was performed with the objective of determining the thermal stability, as well as the influence of GNP content (0.5-2.5 wt.\%) on the thermal properties of PPF. The TGA thermograms and derivative mass loss (dTG) curves of PPF/GNP nanocomposites with different filler content at a heating rate of $10^{\circ} \mathrm{C} / \mathrm{min}$ under nitrogen atmosphere are shown in Figure 3. In Figure 3a, the TGA curve of the GNPs is also presented (dashed curve) for comparative purposes. Analyzing the TGA results, it can be deduced that no remarkable mass loss has occurred until $325^{\circ} \mathrm{C}$, proving the excellent thermal stability of PPF-based materials. Mass loss curves of all studied samples are seemingly almost identical up to $\sim 40{ }^{\circ} \mathrm{C}$, consisting of a one-step procedure and obtaining the same curve shape. Above $400{ }^{\circ} \mathrm{C}$ the neat PPF and PPF/GNP nanocomposites decomposed. The residual amount of the nanocomposites increased with increasing the content of GNPs, indicating that thermal decomposition of PPF is retarded in the nanocomposites, due to the decomposition of GNPs that have initial degradation temperature above $600{ }^{\circ} \mathrm{C}$ (TGA thermograms of GNPs- dashed curve). From the dTG curves, it can be concluded that the degradation is carried out as a one-step process for all the studied samples as only one peak is observed. Concerning the effect of filler's content on the thermal properties of PPF, GNPs seem to have little effect on the temperature that the maximum decomposition rate takes place $T_{d, \max }$, Table 1 . A very small enhancement in thermal stability at the initial stage of degradation, of nearly $3{ }^{\circ} \mathrm{C}$, and $6{ }^{\circ} \mathrm{C}$ appeared for PPF/0.5 GNP, and PPF/2.5GNP composites, respectively, using the temperature at $2 \%$ weight loss as a comparison point. Thermal stability is very important for polymeric materials as it is often the limiting factor both in processing and in end-use applications.

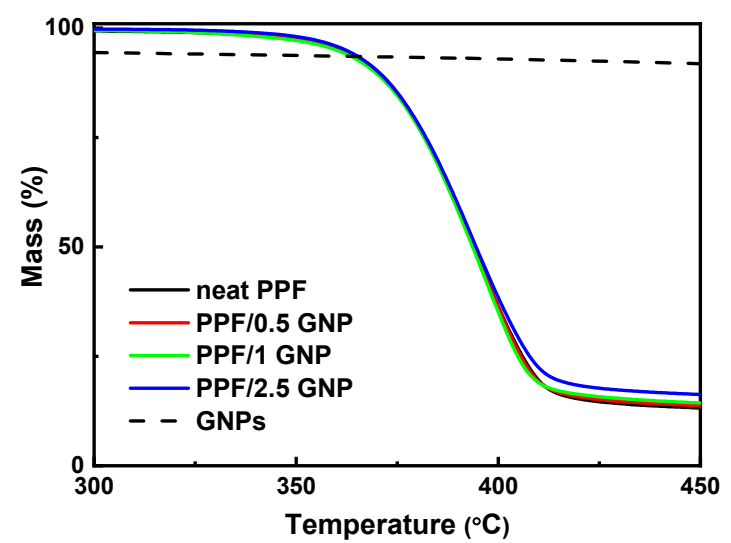

(a)

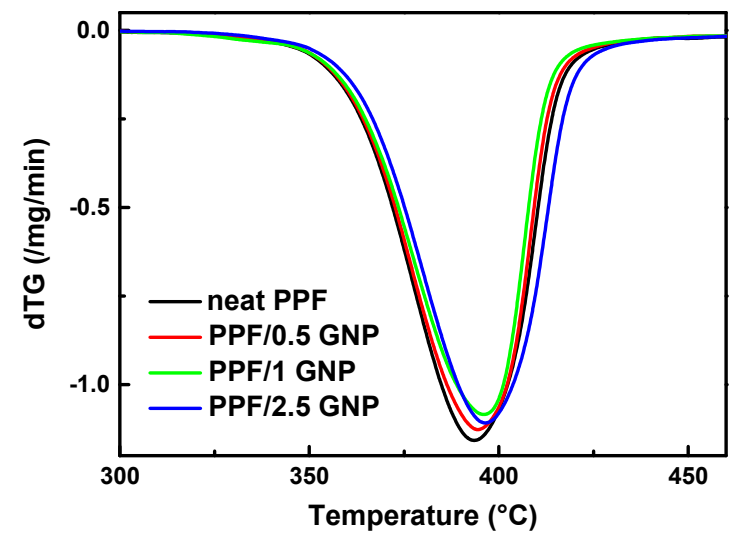

(b)

Figure 3. (a) TGA thermograms; (b) dTG curves of PPF/GNP nanocomposites with different weight fractions of GNPs recorded with the heating rate of $10^{\circ} \mathrm{C} / \mathrm{min}$ under a nitrogen atmosphere.

Table 1. TGA results of all studied samples.

\begin{tabular}{cc}
\hline Sample & $\mathbf{T}_{\mathbf{d}, \max }\left({ }^{\circ} \mathbf{C}\right)$ \\
\hline Neat PPF & 393.2 \\
PPF/0.5 GNP & 394.2 \\
PPF/1 GNP & 395.9 \\
PPF/2.5 GNP & 396.3 \\
\hline
\end{tabular}

\subsection{Thermal Degradation Mechanism of Neat PPF and PPF/2.5GNP Nanocomposite}

As was already concluded from the mass loss curves (TGA) and dTG of the PPF/GNP nanocomposites with $0.5,1$ and $2.5 \mathrm{wt} . \%$ of GNPs that the difference between them is very small. In order to analyze more thoroughly the degradation mechanism of PPF and PPF/2.5 GNP composite, the composite which presented the highest thermal stability enhancement, kinetic parameters (activation 
energy $E$, pre-exponential factor $A$ ) and the conversion function $\mathrm{f}(\alpha)$ must be evaluated. So, neat PPF and PPF/2.5GNP nanocomposite was studied using a model fitting method. The relationship between kinetic parameters and extent of conversion $(\alpha)$ for neat PPF and PPF/2.5 GNP nanocomposite can be found using the mass curves recorded at four heating rates of $5,10,15$, and $20^{\circ} \mathrm{C} / \mathrm{min}$ under nitrogen (Figure 4).

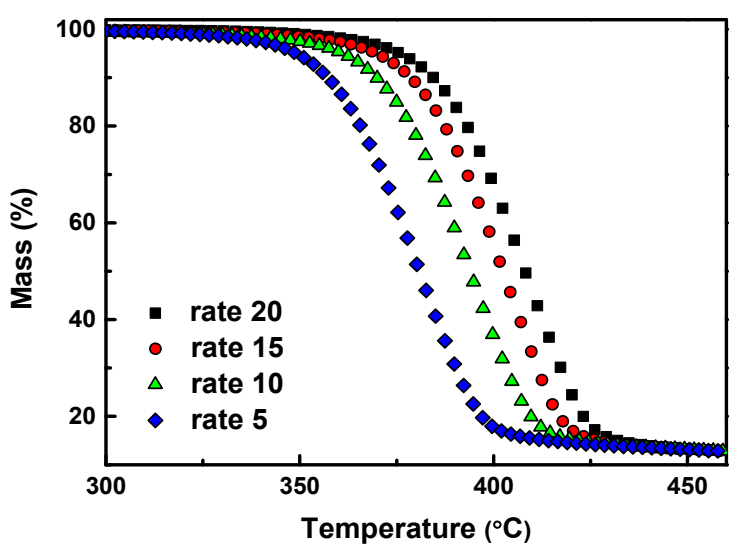

(a)

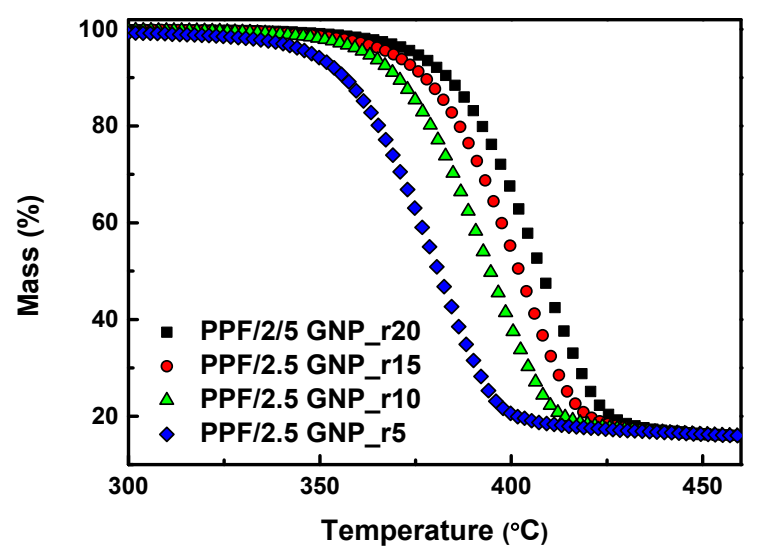

(b)

Figure 4. Mass (\%) curves of (a) neat PPF; (b) PPF/2.5 GNP nanocomposite at heating rates of 5, 10, 15, and $20{ }^{\circ} \mathrm{C} / \mathrm{min}$ under nitrogen.

For the determination of the activation energy by using multiple heating rates, two iso-conversional methods were used: (1) the integral method of Ozawa, Flynn and Wall (OFW) [66], and (2) the isoconversional method of Friedman [67]. The calculated values of activation energy versus the extent of conversion $\alpha$ for neat PPF and PPF/2.5 GNP nanocomposite is shown in Figure 5. The differences in the values of E calculated by the OFW and Friedman methods can be explained by a systematic error due to improper integration [68]. According to Figure 5, it seems that the calculated activation energy values of neat PPF and PPF/2.5 GNP nanocomposite slightly increase with increasing the extent of conversion " $\alpha$ " presenting less variability among the mean value, especially in the case of the OFW plot. The mean values of neat PPF and PPF/GNP nanocomposites were found to be 193.5 and $195.8 \mathrm{~kJ} / \mathrm{mol}$ and 183.5 and $188.5 \mathrm{~kJ} / \mathrm{mol}$ using Friedman and OFW methods, respectively.

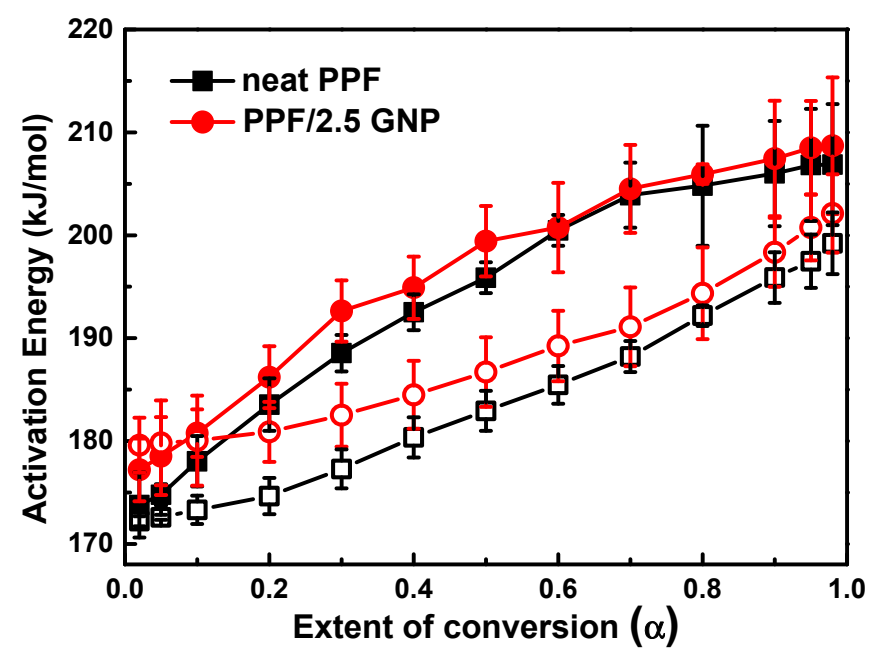

Figure 5. The dependence of activation energy (E) on the extent of conversion $(\alpha)$ for the thermal degradation of neat PPF and PPF/2.5GNP nanocomposite as calculated by Friedman method (filled symbols), and Ozawa Flynn Wall analysis (open symbols). 
Model-fitting was complementary used in the thermal degradation studies of these materials. This method involves fitting different models to $\alpha$ versus temperature curves and simultaneously determining the activation energy $E$ and the pre-exponential factor $A$. So, the kinetic model and the parameters for the four heating rates were determined by multivariate non-linear regression method. For this reason, 16 different reaction models were examined through the comparison of the experimental and theoretical data for the conversion range of $0<\alpha<1$. First, it is considered that the degradation of the samples can be described only by one mechanism, without presuming the exact mechanism. If the result of the fitting cannot be considered as accepted, then we must proceed to the fitting of the experimental data with a combination of two mechanisms.

The form of the conversion function, given by the best fitting for the neat PPF, is the mechanism of autocatalysis n-order $(C n)$ described by the equation $f(\alpha)=(1-\alpha)^{n}\left(1+K_{\text {cat }} X\right)$, where $K_{\text {cat }}$ is the autocatalysis rate constant and $X$ the extent of conversion of the autocatalytic reactions. The results of the fitting can be seen for neat PPF (continuous black lines) in Figure 6 with a correlation coefficient of 0.9998; small divergences appear in the final stages of degradation. However, there isn't any further improvement in the quality of the fitting using two or more reaction mechanisms, since the differences among the regression coefficient values are rather small.

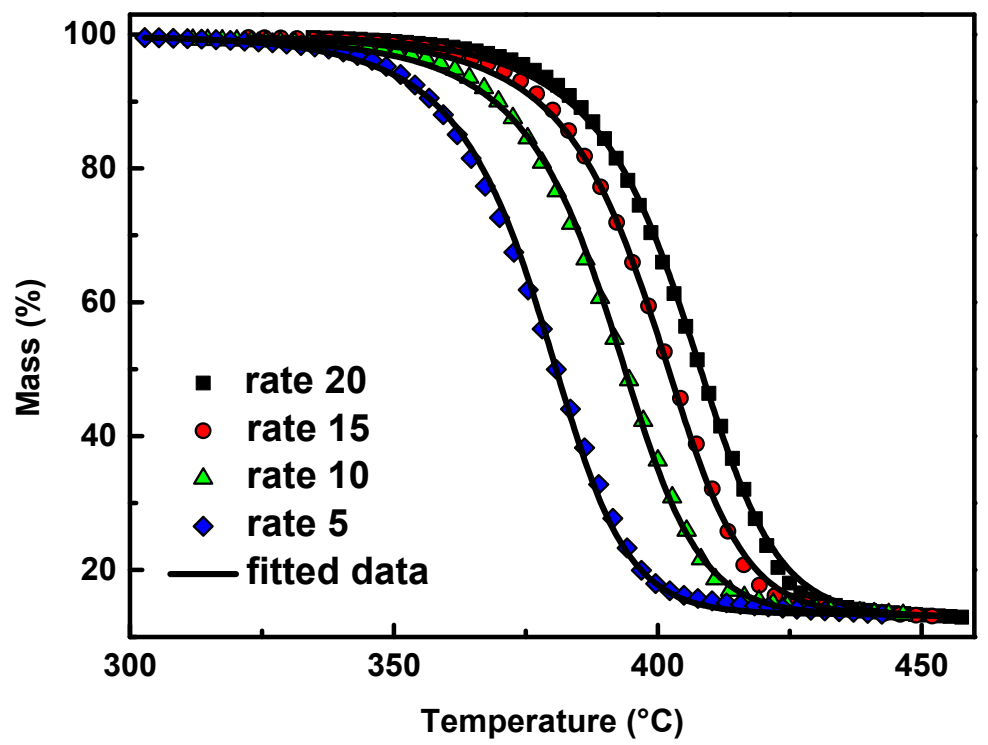

Figure 6. Mass (\%) curves of neat PPF at heating rates of 5, 10, 15, and $20{ }^{\circ} \mathrm{C} / \mathrm{min}$ in a nitrogen atmosphere (symbols) and the corresponding fitting curves with the $\mathrm{Cn}$ reaction model (continuous black lines).

Multivariate non-linear regression method also indicated that the $\mathrm{Cn}$ model, the mechanism of autocatalysis n-order, fit better to thermal decomposition of PPF/2.5 GNP nanocomposite with a correlation coefficient value of 0.9998 , Figure 7 . This is in consistence with the iso-conversional method (Figure 5) in which the activation energy of materials slightly increases with increasing the extent of conversion, suggesting that a single-step reaction mechanism may efficiently describe the degradation.

The calculated values of the activation energy, pre-exponential factor and the reaction order for PPF and PPF/2.5 GNP nanocomposite using the nth-order with autocatalysis ( $\mathrm{Cn}$ ) model are summarized in Table 2. It was found that the same model describes the reaction mechanism of both neat PPF and PPF/2.5 GNP nanocomposite. It is worthwhile noting that that the activation energy values are close to the ones calculated from OFW analysis, as well as Friedman's method (Figure 5). Comparing the activation energies, PPF/2.5 GNP nanocomposite has slightly higher values than neat PPF. This improvement in thermal stability of nanocomposite is associated with the 2-dimensional planar structure of GNPs. The mobility of polymer matrix is restricted, and the chemical reactivity 
of the corresponding chains is lower increasing activation energy and eventually retarding more the thermal degradation of the nanocomposites.

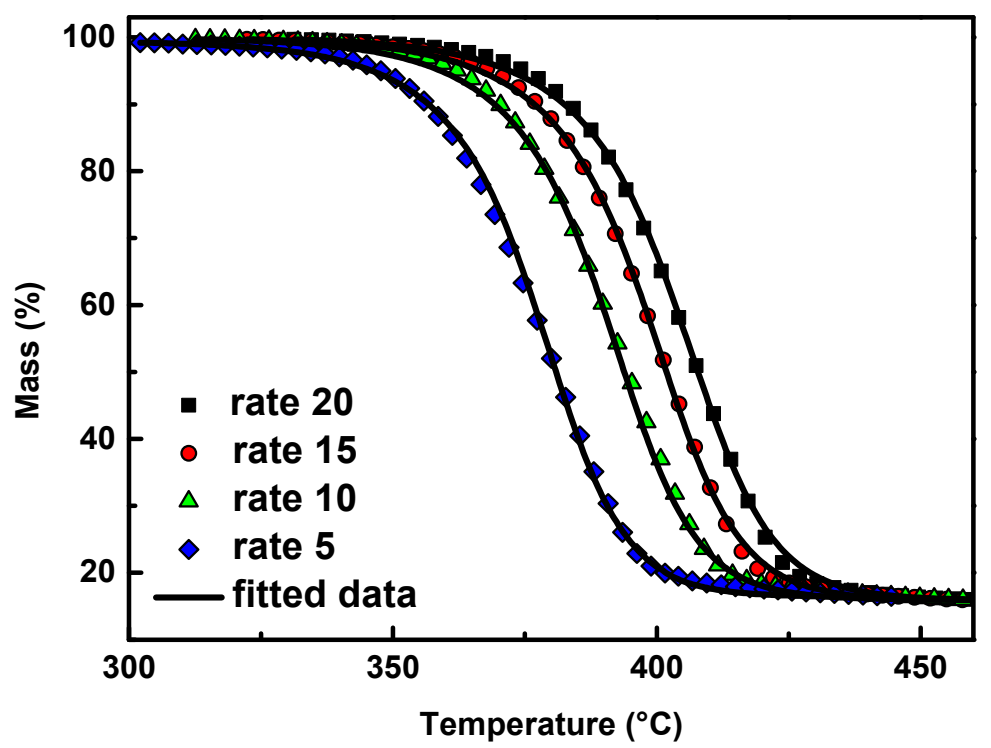

Figure 7. Mass (\%) curves of PPF/2.5 GNP nanocomposite at heating rates of 5, 10, 15, and $20^{\circ} \mathrm{C} / \mathrm{min}$ in a nitrogen atmosphere (symbols) and the corresponding fitting curves with the $\mathrm{Cn}$ model (continuous black lines).

Table 2. Activation energy, pre-exponential factor and reaction order of neat PPF and PPF/2.5 GNP nanocomposite.

\begin{tabular}{ccccccc}
\hline Sample & Mechanism & $\begin{array}{c}\text { Activation } \\
\text { Energy/kJmol-1 }^{-1}\end{array}$ & $\begin{array}{c}\text { Pre-exponential } \\
\text { Factor/s } \mathbf{s}^{-\mathbf{1}}\end{array}$ & $\begin{array}{c}\text { Reaction } \\
\text { Order/n }\end{array}$ & Log $\mathbf{K}_{\text {cat }}$ & $\begin{array}{c}\text { Regression } \\
\text { Coefficient }\end{array}$ \\
\hline Neat PPF & $\mathrm{Cn}$ & 187.0 & 12.2 & 1.36 & 0.81 & 0.9998 \\
PPF/2.5 GNP & $\mathrm{Cn}$ & 191.1 & 12.6 & 1.43 & 0.82 & 0.9998 \\
\hline
\end{tabular}

The degradation mechanism was afterwards studied with Py-GC/MS measurements. The compounds are pyrolyzed in a pre-selected temperature and followed by the separation of the evolved pyrolysis products by a GC capillary column and subsequent detection via mass spectroscopy. This method enables the determination of the exact degradation routes that take place when a polymeric material is heated in high temperatures in inert atmosphere.

The degradation mechanisms of furan-based polyesters were first studied by our group, including this of PPF $[23,69]$. In general, they follow the degradation paths of their terephthalate homologues. Similarly to all polyesters with $\beta$-hydrogen atoms on their macromolecular chains, they degrade mainly by heterolytic scission reactions of the hydrogen in $\beta$ position to the ester bond [70-73]. This degradation route leads to the evolution of vinyl-ended and carboxyl-ended products. Additionally, homolytic scission reactions of the acyl-oxygen and alkyl-oxygen bonds can occur, especially under higher pyrolysis temperatures [24,31].

Total ion chromatographs of PPF and PPF/2.5 GNP after pyrolysis at $360^{\circ} \mathrm{C}$ and $400^{\circ} \mathrm{C}$ are presented in Figure 8 and the corresponding compounds, identified via their mass spectra, are presented in Table 3. As expected, the main pyrolysis products are vinyl- and carboxyl- ended molecules that result from $\beta$-scission reactions (Scheme 2). Other classes of products are some hydroxyl-ended, methoxy-ended molecules as well as some aldehydes. It should be noted that since the mass spectra of the molecular ions of aldehydes are very weak, we cannot be completely confident about their identification even though they are known to be released from polyesters during heating. All the possible degradation routes have been explained in detail in our previous publications [22,24,25,31,69,74]. 
In both samples, the pyrolysis products identified were identical, meaning that GNP doesn't affect the degradation mechanism of PPF. The slight increase in the activation of energy calculated by TGA is caused by the ability of graphene layers to hinder gas diffusion in the polymeric matrix as they can reduce chain mobility $[75,76]$. When comparing the GC patterns of PPF and PPF/2.5 GNP it is observed that while they don't have any noteworthy differences at $400^{\circ} \mathrm{C}$, there is a significant increase in the intensity of some peaks, in the presence of GNP at $360^{\circ} \mathrm{C}$ suggesting their larger relative amount. Those peaks in $\mathrm{Rt}=7.00,7.35,11.19,11.30,17.76,20.27,21.19$ and $21.58 \mathrm{~min}$ are highlighted in Figure 8a and the majority was identified as compounds that are produced via secondary degradation routes, including -OH ended compounds from acyl-oxygen homolysis and aldehydes from $\alpha$-hydrogen bond scission. Therefore, the presence of GNP in the PPF matrix resulted in a pronounced occurrence of homolytic degradation reactions in comparison with neat PPF.

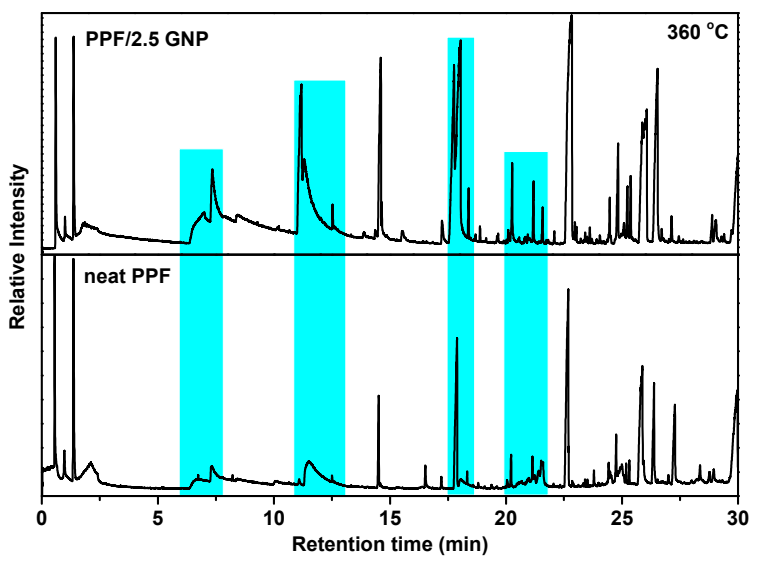

(a)

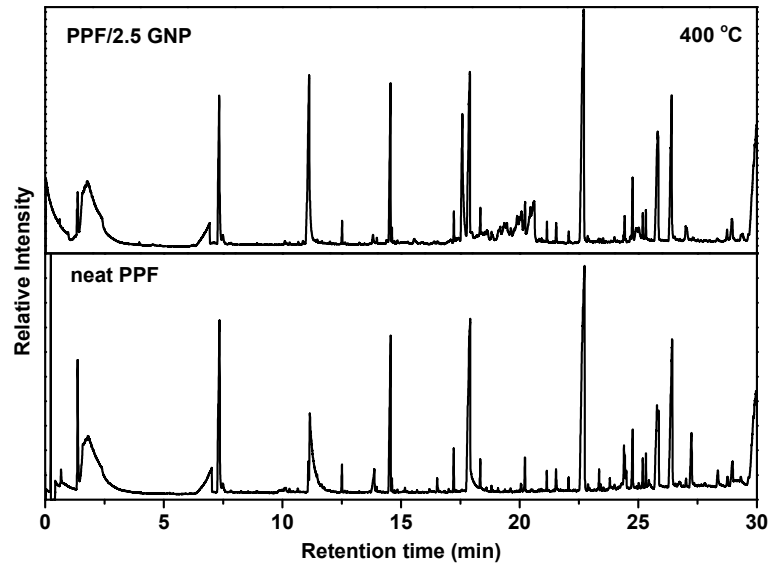

(b)

Figure 8. Total Ion Gas chromatographs of neat PPF and PPF/2.5 GNP after pyrolysis at (a) $360{ }^{\circ} \mathrm{C}$; (b) $400{ }^{\circ} \mathrm{C}$. The highlighted peaks correspond to compounds that are evolved via secondary degradation routes.

Table 3. Possible pyrolysis products of neat PPF and PPF/2.5 GNP nanocomposite.

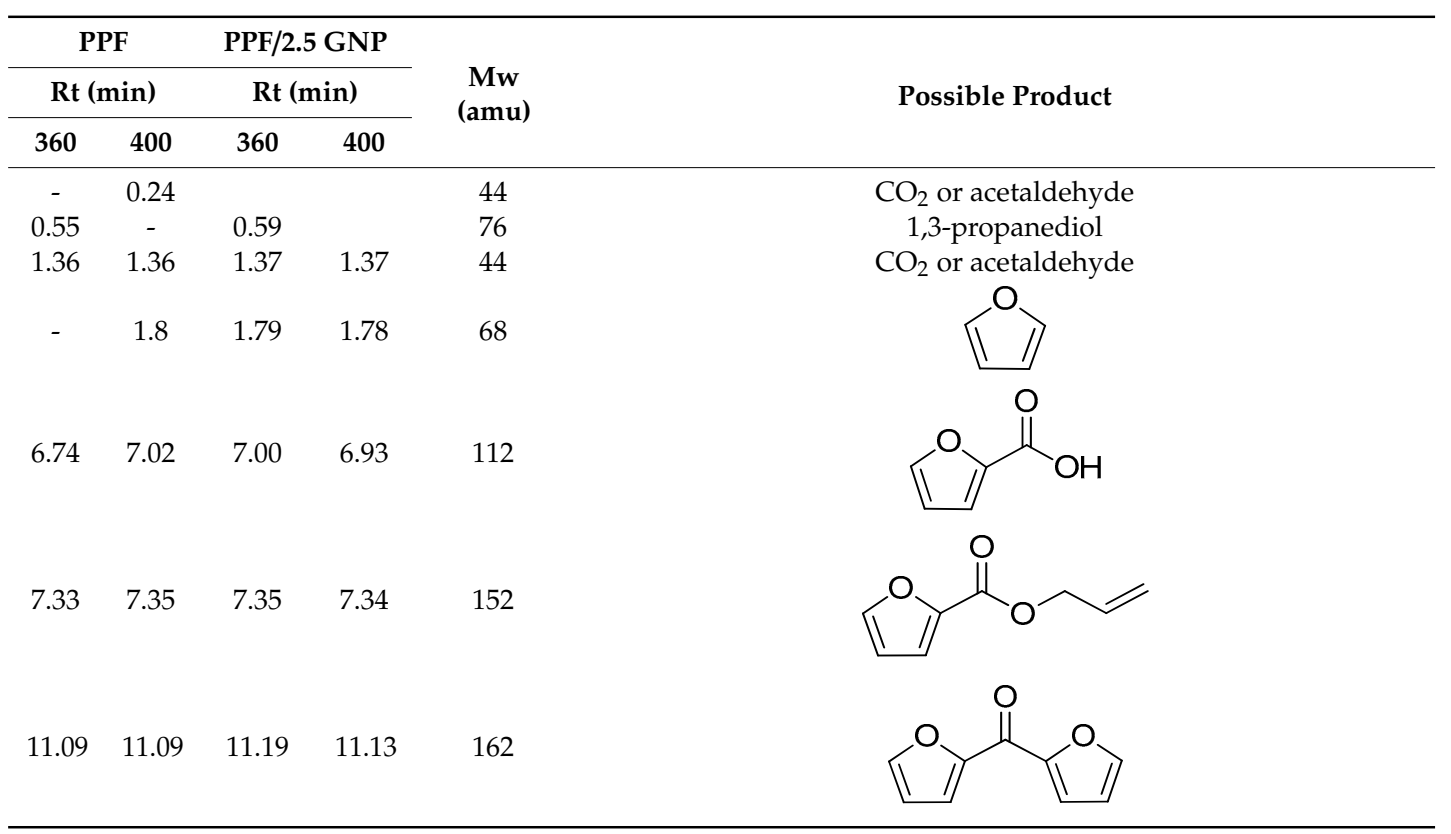


Table 3. Cont.

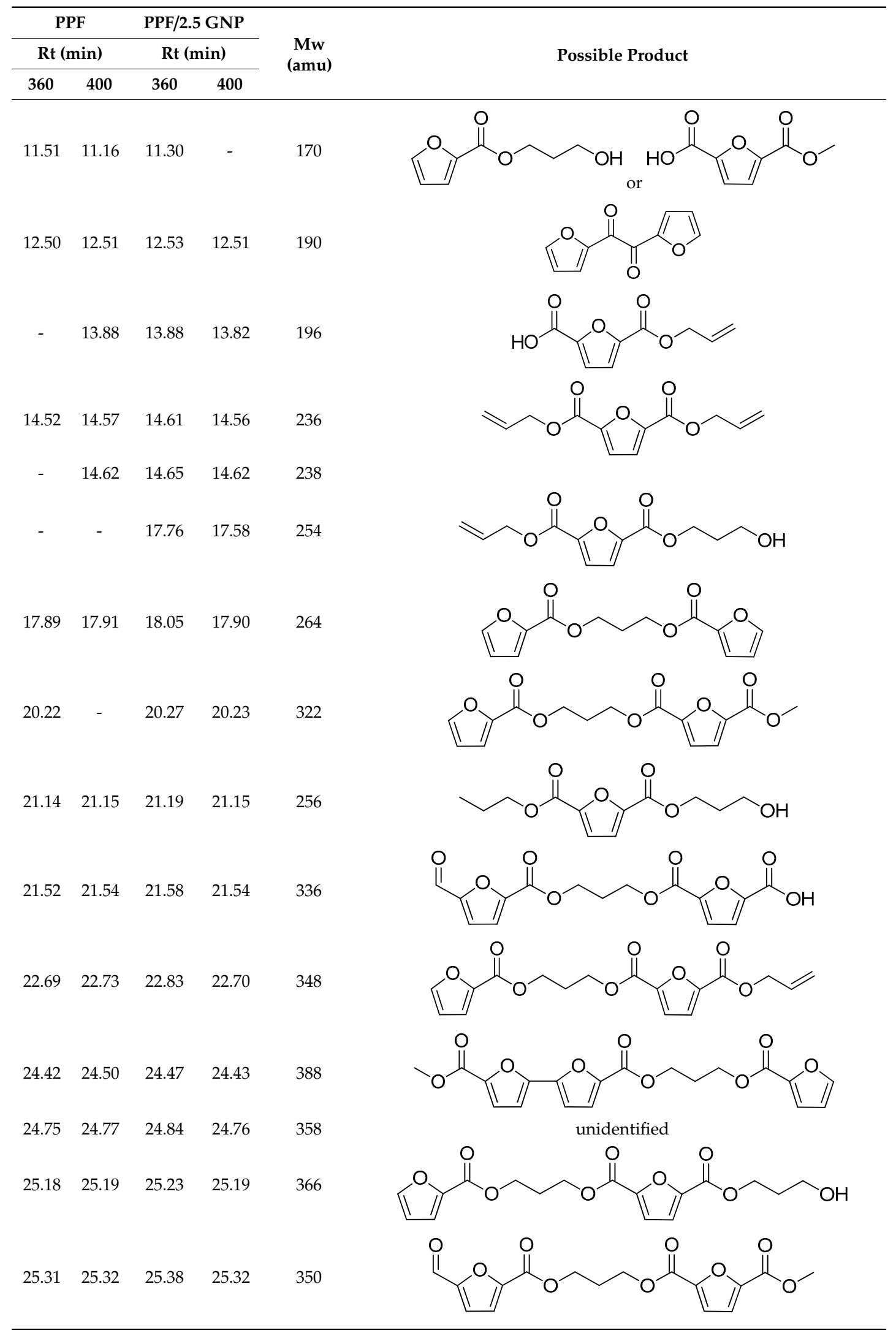


Table 3. Cont.

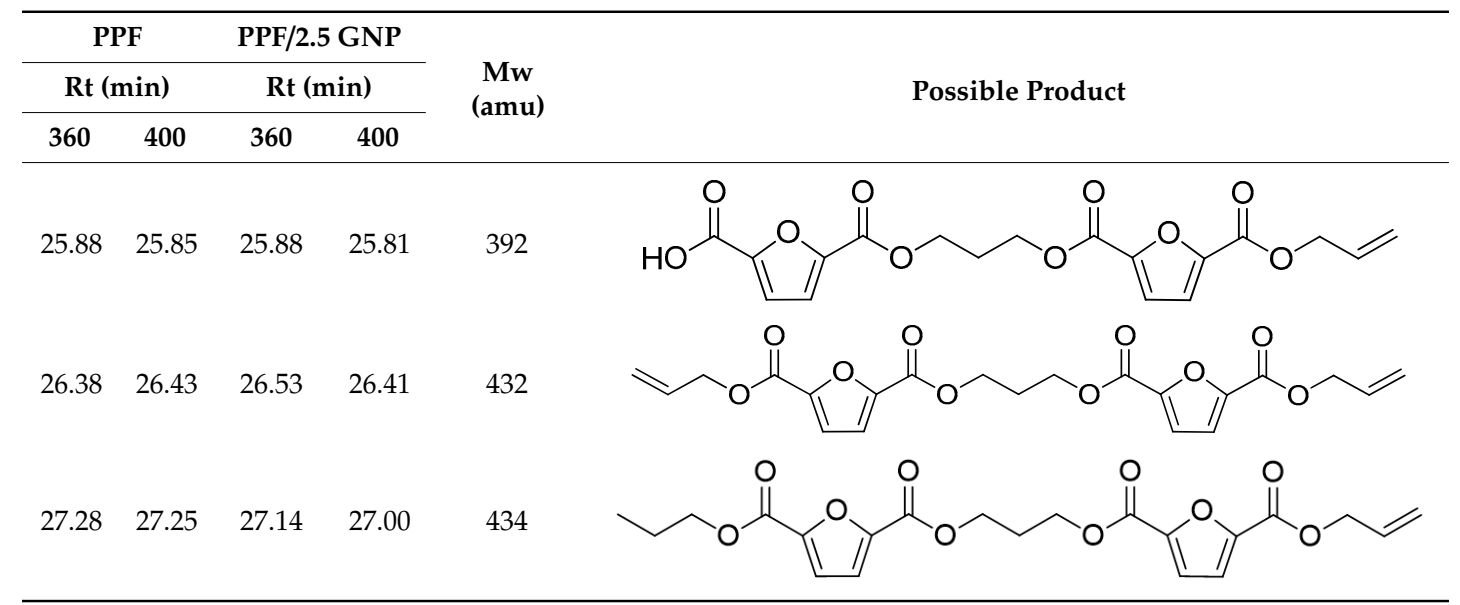<smiles>C=CCOC(=O)c1ccc(C(=O)OC)o1</smiles>

Scheme 2. Basic degradation routes of PPF.

\section{Materials and Methods}

\subsection{Materials}

2,5-Furandicarboxylic acid (purum 97\%), propylene glycol anhydrous 99.6\% (PG) and tetrabutyltitanate (TBT) catalyst of analytical grade were purchased from Sigma-Aldrich (Taufkirchen, Germany). GNPs with the trade name $x G n P^{\circledR}$ - Grade M were supplied by XGSciences (Lansing MI, USA). According to the manufacturer, the nanoplatelets have an average thickness of $6-8 \mathrm{~nm}$, surface area $120-150 \mathrm{~m}^{2} / \mathrm{g}$ and average particle diameter of $5 \mu \mathrm{m}$. All other materials and solvents used were of analytical grade and were purchased from Sigma-Aldrich.

\subsection{Synthesis of 2,5-Dimethylfuran-dicarboxylate (DMFD)}

2,5-Furandicarboxylic acid (15.6 g), anhydrous methanol (200 $\mathrm{mL})$ and concentrated sulfuric acid $(2 \mathrm{~mL})$ were placed in a round bottom flask $(500 \mathrm{~mL})$ and the mixture was refluxed for $5 \mathrm{~h}$. The excess of the methanol was distilled off, and the solution was filtered through a disposable Teflon membrane filter. During filtration, dimethylfurandicarboxylate (DMFD) was precipitated as white powder and, after cooling, distilled water $(100 \mathrm{~mL})$ was added. The dispersion was partially neutralized by adding $\mathrm{Na}_{2} \mathrm{CO}_{3} 5 \%$ w/v during stirring, while $\mathrm{pH}$ was measured continuously. The white powder was filtered 
and the solid was washed several times with distilled water and dried. The isolated white dimethyl ester was recrystallized with a mixture of 50/50 v/v methanol/water. After cooling, 2,5-DMFD was precipitated in the form of white needles. The reaction yield was calculated at $75 \%$.

\subsection{PPF and Nanocomposites Synthesis}

PPF was synthesized through the two-stage melt polycondensation (esterification and polycondensation) in a glass batch reactor [21]. DMFD and propylene glycol in a molar ratio of diester/diol $=1 / 2.2$ were charged into the reaction tube of the polyesterification apparatus with $500 \mathrm{ppm}$ of TBT. The reaction mixture was heated at $160{ }^{\circ} \mathrm{C}$ under argon flow for $1.5 \mathrm{~h}$, at $170{ }^{\circ} \mathrm{C}$ for additional $1.5 \mathrm{~h}$ and finally at $180{ }^{\circ} \mathrm{C}$ for $2 \mathrm{~h}$. This first step (transesterification) is considered complete after the collection of almost all the theoretical amount of $\mathrm{CH}_{3} \mathrm{OH}$, which was removed from the reaction mixture by distillation and collected in a graduate cylinder. In the second step of polycondensation, vacuum (5.0 Pa) was applied slowly over a time of about $30 \mathrm{~min}$ to remove the excess of diol, to avoid excessive foaming and to minimize oligomer sublimation, which is a potential problem during the melt polycondensation. The temperature was gradually increased $(1.5 \mathrm{~h})$ to $22{ }^{\circ} \mathrm{C}$, while stirring speed was also increased to $720 \mathrm{rpm}$. The reaction continued at this temperature for $1.5 \mathrm{~h}$. Successively, the temperature was increased to $235^{\circ} \mathrm{C}$ for $1.5 \mathrm{~h}$ and to $250{ }^{\circ} \mathrm{C}$ for additional $2 \mathrm{~h}$. PPF-based GNP nanocomposites containing $0.5,1$ and $2.5 \mathrm{wt}$.\% of GNPs were in-situ prepared using also the two-stage melt polycondensation method. Nanofillers were added to the propylene glycol and the dispersion was subjected to sonication for $15 \mathrm{~min}$ to obtain a uniform dispersion. Afterwards, the dispersion was added to the reaction tube together with DMFD and TBT catalyst. The reaction continued, as above described for the synthesis of neat PPF. After the polycondensation reaction was completed, neat PPF and PPF/GNP nanocomposites were easily removed, milled and washed with methanol.

\subsection{Intrinsic Viscosity Measurements}

Intrinsic viscosity $[\eta]$ measurements were performed using a Cannon Ubbelohde viscometer (State College, PA, USA) at $30{ }^{\circ} \mathrm{C}$ in a mixture of phenol/1,1,2,2-tetrachloroethane $(60 / 40, w / w)$. The sample was kept in the above-mentioned mixture at $90{ }^{\circ} \mathrm{C}$ until complete dissolution was achieved. The solution was then cooled to room temperature and filtered through a Teflon disposable membrane filter.

\subsection{Nuclear Magnetic Resonance (NMR)}

${ }^{1} \mathrm{H}-\mathrm{NMR}$ spectra of polyesters were obtained with a Bruker spectrometer (Billerica, MA, USA) operating at a frequency of $400 \mathrm{MHz}$. A sample concentration equal to $5 \% w / v$ in deuterated trifluoroacetic acid (d-TFA) was used. The number of scans was 10 and the sweep width was $6 \mathrm{kHz}$.

\subsection{Wide Angle X-Ray Diffraction Patterns (WAXD)}

X-ray diffraction measurements of the samples were performed using a MiniFlex II XRD system from Rigaku Co. (Tokyo, Japan), with $\mathrm{CuK}_{\alpha}$ radiation $(\lambda=0.154 \mathrm{~nm})$ in the angle $2 \theta$ range from $5^{\circ}$ to $60^{\circ}$.

\subsection{Thermogravimetric Analysis (TGA)}

Thermogravimetric analysis of the PPF and PPF/GNP nanocomposites were carried out using a SETARAM SETSYS TG-DTA 16/18 instrument (Caluire, France) by heating the samples from 25 to $600{ }^{\circ} \mathrm{C}$ in a $50 \mathrm{~mL} / \mathrm{min}$ flow of $\mathrm{N}_{2}$ at a heating rate of $10^{\circ} \mathrm{C} / \mathrm{min}$. For the kinetic analysis study, neat PPF and PPF/GNP nanocomposites with $2.5 \mathrm{wt} . \%$ filler content (PPF/2.5 GNP) were heated at four different heating rates, namely $5,10,15$, and $20^{\circ} \mathrm{C} / \mathrm{min}$. Samples $(4.5 \pm 0.5 \mathrm{mg})$ were placed in alumina crucibles, while an empty alumina crucible was used as a reference. Continuous recordings of sample temperature, sample weight, first derivative, and heat flow were taken. 


\subsection{Pyrolysis-Gas Chromatography-Mass Spectroscopy (Py-GC/MS)}

For Py-GC/MS analysis of polyesters a very small amount of each material is "dropped" initially into the "Double-Shot" EGA/PY-3030D Pyrolyzer (Frontier Laboratories Ltd., Fukushima Japan) using a CGS-1050Ex (Kyoto, Japan) carrier gas selector. For pyrolysis analysis (flash pyrolysis) each sample was placed into the sample cup which afterwards fell free into the Pyrolyzer furnace. The pre-selected pyrolysis temperatures were 360 and $400{ }^{\circ} \mathrm{C}$ and the GC oven temperature was heated from 50 to $300^{\circ} \mathrm{C}$ at $20^{\circ} \mathrm{C} / \mathrm{min}$. Those two temperatures were selected based on the EGA pyrogram and represent the sample prior and after thermal decomposition. Sample vapors generated in the furnace were split (at a ratio of 1/50), a portion moved to the column at a flow rate of $1 \mathrm{~mL} / \mathrm{min}$, pressure $53.6 \mathrm{kPa}$ and the remaining portion exited the system via the vent. The pyrolyzates were separated using temperature programmed capillary column of a Shimadzu QP-2010 Ultra Plus (Kyoto, Japan) gas chromatograph and analysed by a Shimadzu MS-QP2010SE mass spectrometer at $70 \mathrm{eV}$. Ultra ALLOY ${ }^{\circledR}$ metal capillary column from Frontier Laboratories Ltd. (Fukushima, Japan) was used containing 5\% diphenyl and $95 \%$ dimethylpolysiloxane stationary phase, column length $30 \mathrm{~m}$ and column ID $0.25 \mathrm{~mm}$. For the mass spectrometer the following conditions were used: Ion source heater $200^{\circ} \mathrm{C}$, interface temperature $300^{\circ} \mathrm{C}$, vacuum $10^{-4}-10^{0} \mathrm{~Pa}, \mathrm{~m} / \mathrm{z}$ range $10-500 \mathrm{amu}$ and scan speed 10.000 . The chromatograph and spectra retrieved by each experiment were subjected to further interpretation through Shimadzu and Frontier post-run software (Kyoto, Japan).

\section{Conclusions}

In this work, PPF/GNP nanocomposites containing 0.5, 1 and $2.5 \mathrm{wt} . \%$ GNPs were successfully synthesized via the in-situ transesterification and polycondensation method. The addition of GNPs did not affect the intrinsic viscosity, or the chemical structure of the nanocomposites as shown by the ${ }^{1} \mathrm{H}-\mathrm{NMR}$ spectra and the viscosity measurements. The crystallinity of the as received materials was assessed by WAXD measurements. The diffractograms showed that the materials are amorphous. Thermal properties with focus on thermal stability and degradation mechanism were evaluated. All samples had strong thermal stability, as no remarkable mass loss was observed until $325^{\circ} \mathrm{C}$ and have been decomposed in similar one-step procedures as shown in the dTG curves. The study of degradation kinetics through thermogravimetry revealed a small increase in the activation energy value for the nanocomposite with $2.5 \mathrm{wt}$.\% GNP in comparison with neat PPF. The nanofillers did not alter the degradation pathways of PPF, as both the $\beta$-scission and the acyl-oxygen homolysis occur. Instead, they affected the balance between the primary heterolytic scission reactions and the homolytic degradation routes. The presence of GNP in the PPF matrix resulted in a pronounced occurrence of homolytic degradation reactions in comparison with neat PPF as more -OH ended compounds were detected in the chromatographs.

Author Contributions: Conceptualization, D.N.B. and D.G.P.; methodology, L.P., Z.T. and E.T.; investigation, Z.T., E.T., L.P. and N.K.; formal analysis, Z.T. and E.T.; writing-original draft preparation, E.T., Z.T. and L.P.; writing-review and editing, Z.T., G.Z.P. and D.G.P.; supervision, D.N.B. and K.C.

Conflicts of Interest: The authors declare no conflict of interest.

\section{References}

1. Bornscheuer, U.T. Feeding on plastic. Science 2016, 351, 1154-1155. [CrossRef]

2. Zhu, Y.; Romain, C.; Williams, C.K. Sustainable polymers from renewable resources. Nature 2016, 540, 354-362. [CrossRef]

3. Schneiderman, D.K.; Hillmyer, M.A. 50th Anniversary Perspective: There Is a Great Future in Sustainable Polymers. Macromolecules 2017, 50, 3733-3749. [CrossRef]

4. Gandini, A.; Silvestre, A.J.D.; Neto, C.P.; Sousa, A.F.; Gomes, M. The furan counterpart of poly(ethylene terephthalate): An alternative material based on renewable resources. J. Polym. Sci. Part A Polym. Chem. 2009, 47, 295-298. [CrossRef] 
5. Haider, T.P.; Völker, C.; Kramm, J.; Landfester, K.; Wurm, F.R. Plastics of the Future? The Impact of Biodegradable Polymers on the Environment and on Society. Angew. Chem. Int. Ed. 2019, 58, 50-62. [CrossRef]

6. Sustainability. Available online: https://ec.europa.eu/epsc/topics/sustainability_en (accessed on 28 March 2019).

7. Xie, H.; Wu, L.; Li, B.-G.; Dubois, P. Biobased Poly(ethylene-co-hexamethylene 2,5-furandicarboxylate) (PEHF) Copolyesters with Superior Tensile Properties. Ind. Eng. Chem. Res. 2018, 57, 13094-13102. [CrossRef]

8. Xie, H.; Wu, L.; Li, B.-G.; Dubois, P. Poly(ethylene 2,5-furandicarboxylate-mb-poly(tetramethylene glycol)) multiblock copolymers: From high tough thermoplastics to elastomers. Polymer (Guildf) 2018, 155, 89-98. [CrossRef]

9. Bio-Based Products. Available online: http://ec.europa.eu/growth/sectors/biotechnology/bio-based-products_ is (accessed on 28 March 2019).

10. Legrand, S.; Jacquel, N.; Amedro, H.; Saint-Loup, R.; Pascault, J.-P.; Rousseau, A.; Fenouillot, F. Synthesis and properties of poly (1,4-cyclohexanedimethylene-co-isosorbide terephthalate), a biobased copolyester with high performances. Eur. Polym. J. 2019, 115, 22-29. [CrossRef]

11. Blache, H.; Méchin, F.; Rousseau, A.; Fleury, É.; Pascault, J.-P.; Alcouffe, P.; Jacquel, N.; Saint-Loup, R. New bio-based thermoplastic polyurethane elastomers from isosorbide and rapeseed oil derivatives. Ind. Crops Prod. 2018, 121, 303-312. [CrossRef]

12. Delidovich, I.; Hausoul, P.J.C.; Deng, L.; Pfútzenreuter, R.; Rose, M.; Palkovits, R. Alternative monomers based on lignocellulose and their use for polymer production. Chem. Rev. 2015, 116, 1540-1599. [CrossRef]

13. Gandini, A.; Lacerda, T.M.; Carvalho, A.J.F.; Trovatti, E. Progress of Polymers from Renewable Resources: Furans, Vegetable Oils, and Polysaccharides. Chem. Rev. 2016, 116, 1637-1669. [CrossRef]

14. Agriculture, U.S.D. of WHAT IS BIOPREFERRED? Available online: https://www.biopreferred.gov/ BioPreferred/faces/pages/AboutBioPreferred.xhtml (accessed on 28 March 2019).

15. Shi, Z.; Jia, C.; Wang, D.; Deng, J.; Xu, G.; Wu, C.; Dong, M.; Guo, Z. Synthesis and characterization of porous tree gum grafted copolymer derived from Prunus cerasifera gum polysaccharide. Int. J. Biol. Macromol. 2019, 133, 964-970. [CrossRef]

16. Hu, Q.; Zhou, N.; Gong, K.; Liu, H.; Liu, Q.; Sun, D.; Wang, Q.; Shao, Q.; Liu, H.; Qiu, B.; et al. Intracellular Polymer Substances Induced Conductive Polyaniline for Improved Methane Production from Anaerobic Wastewater Treatment. ACS Sustain. Chem. Eng. 2019, 7, 5912-5920. [CrossRef]

17. Werpy, T.; Petersen, G.; Aden, A.; Bozell, J.; Holladay, J.; White, J.; Manheim, A.; Eliot, D.; Lasure, L.; Jones, S. Top Value Added Chemicals from Biomass. Volume 1-Results of Screening for Potential Candidates from Sugars and Synthesis Gas; Department of Energy: Washington, DC, USA, 2004.

18. Pan, T.; Deng, J.; Xu, Q.; Zuo, Y.; Guo, Q.; Fu, Y. Catalytic Conversion of Furfural into a 2,5-Furandicarboxylic Acid-Based Polyester with Total Carbon Utilization. ChemSusChem 2013, 6, 47-50. [CrossRef]

19. Papageorgiou, G.Z.; Tsanaktsis, V.; Papageorgiou, D.G.; Chrissafis, K.; Exarhopoulos, S.; Bikiaris, D.N. Furan-based polyesters from renewable resources: Crystallization and thermal degradation behavior of poly(hexamethylene 2,5-furan-dicarboxylate). Eur. Polym. J. 2014, 67, 383-396. [CrossRef]

20. Papageorgiou, G.Z.; Tsanaktsis, V.; Papageorgiou, D.G.; Exarhopoulos, S.; Papageorgiou, M.; Bikiaris, D.N. Evaluation of polyesters from renewable resources as alternatives to the current fossil-based polymers. Phase transitions of poly(butylene 2,5-furan-dicarboxylate). Polymer (United Kingdom) 2014, 55, 3846-3858. [CrossRef]

21. Papageorgiou, G.Z.; Papageorgiou, D.G.; Tsanaktsis, V.; Bikiaris, D.N. Synthesis of the bio-based polyester poly(propylene 2,5-furan dicarboxylate). Comparison of thermal behavior and solid state structure with its terephthalate and naphthalate homologues. Polymer (United Kingdom) 2015, 62, 28-38. [CrossRef]

22. Tsanaktsis, V.; Terzopoulou, Z.; Exarhopoulos, S.; Bikiaris, D.N.; Achilias, D.S.; Papageorgiou, D.G.; Papageorgiou, G.Z. Sustainable, eco-friendly polyesters synthesized from renewable resources: Preparation and thermal characteristics of poly(dimethyl-propylene furanoate). Polym. Chem. 2015, 6, 8284-8296. [CrossRef]

23. Papadopoulos, L.; Terzopoulou, Z.; Bikiaris, D.N.; Patsiaoura, D.; Chrissafis, K.; Papageorgiou, D.G.; Papageorgiou, G.Z. Synthesis and Characterization of In-Situ-Prepared Nanocomposites Based on Poly(Propylene 2,5-Furan Dicarboxylate) and Aluminosilicate Clays. Polymers (Basel) 2018, 10, 937. [CrossRef] 
24. Terzopoulou, Z.; Kasmi, N.; Tsanaktsis, V.; Doulakas, N.; Bikiaris, D.N.; Achilias, D.S.; Papageorgiou, G.Z. Synthesis and characterization of bio-based polyesters: Poly(2-methyl-1,3-propylene-2,5-furanoate), Poly(isosorbide-2,5-furanoate), Poly(1,4-cyclohexanedimethylene-2,5-furanoate). Materials (Basel) 2017, 10, 801. [CrossRef]

25. Terzopoulou, Z.; Karakatsianopoulou, E.; Kasmi, N.; Majdoub, M.; Papageorgiou, G.Z.; Bikiaris, D.N. Effect of catalyst type on recyclability and decomposition mechanism of poly(ethylene furanoate) biobased polyester. J. Anal. Appl. Pyrolysis 2017, 126, 357-370. [CrossRef]

26. Kasmi, N.; Papageorgiou, G.Z.; Achilias, D.S.; Bikiaris, D.N. Solid-State polymerization of poly(Ethylene Furanoate) biobased Polyester, II: An efficient and facile method to synthesize high molecular weight polyester appropriate for food packaging applications. Polymers (Basel) 2018, 10, 471. [CrossRef]

27. Terzopoulou, Z.; Karakatsianopoulou, E.; Kasmi, N.; Tsanaktsis, V.; Nikolaidis, N.; Kostoglou, M.; Papageorgiou, G.Z.; Lambropoulou, D.A.; Bikiaris, D.N. Effect of catalyst type on molecular weight increase and coloration of poly(ethylene furanoate) biobased polyester during melt polycondensation. Polym. Chem. 2017, 8, 6895-6908. [CrossRef]

28. Achilias, D.S.; Chondroyiannis, A.; Nerantzaki, M.; Adam, K.V.; Terzopoulou, Z.; Papageorgiou, G.Z.; Bikiaris, D.N. Solid State Polymerization of Poly(Ethylene Furanoate) and Its Nanocomposites with $\mathrm{SiO}_{2}$ and $\mathrm{TiO}_{2}$. Macromol. Mater. Eng. 2017, 302, 1-15. [CrossRef]

29. Tsanaktsis, V.; Bikiaris, D.N.; Guigo, N.; Exarhopoulos, S.; Papageorgiou, D.G.; Sbirrazzuoli, N.; Papageorgiou, G.Z. Synthesis, properties and thermal behavior of poly(decylene-2,5-furanoate): A biobased polyester from 2,5-furan dicarboxylic acid. RSC Adv. 2015, 5, 74592-74604. [CrossRef]

30. Papageorgiou, G.Z.; Terzopoulou, Z.; Tsanaktsis, V.; Achilias, D.S.; Triantafyllidis, K.; Diamanti, E.K.; Gournis, D.; Bikiaris, D.N. Effect of graphene oxide and its modification on the microstructure, thermal properties and enzymatic hydrolysis of poly(ethylene succinate) nanocomposites. Thermochim. Acta 2015, 614, 116-128. [CrossRef]

31. Terzopoulou, Z.; Tsanaktsis, V.; Nerantzaki, M.; Papageorgiou, G.Z.; Bikiaris, D.N. Decomposition mechanism of polyesters based on 2,5-furandicarboxylic acid and aliphatic diols with medium and long chain methylene groups. Polym. Degrad. Stab. 2016, 132, 127-136. [CrossRef]

32. Bikiaris, D.N.; Papageorgiou, G.Z.; Giliopoulos, D.J.; Stergiou, C.A. Correlation between Chemical and Solid-State Structures and Enzymatic Hydrolysis in Novel Biodegradable Polyesters. The Case of Poly(propylene alkanedicarboxylate)s. Macromol. Biosci. 2008, 8, 728-740. [CrossRef]

33. Haas, T.; Jaeger, B.; Weber, R.; Mitchell, S.F.; King, C.F. New diol processes: 1,3-propanediol and 1,4-butanediol. Appl. Catal. A Gen. 2005, 280, 83-88. [CrossRef]

34. Kluge, M.; Pérocheau Arnaud, S.; Robert, T. 1,3-Propanediol and its Application in Bio-Based Polyesters for Resin Applications. Chem. Africa 2018. [CrossRef]

35. Wang, B.; Li, C.Y.; Hanzlicek, J.; Cheng, S.Z.D.; Geil, P.H.; Grebowicz, J.; Ho, R.-M. Poly(trimethylene teraphthalate) crystal structure and morphology in different length scales. Polymer (Guildf) 2001, 42, 7171-7180. [CrossRef]

36. Ward, I.M.; Wilding, M.A.; Brody, H. The mechanical properties and structure of poly(m-methylene terephthalate) fibers. J. Polym. Sci. Polym. Phys. Ed. 1976, 14, 263-274. [CrossRef]

37. Nederberg, F.; Bell, R.L.; Torradas, J.M. Furan-based Polymeric Hydrocarbon Fuel Barrier Structures. CN105848891A, 10 August 2016.

38. Sustainable Bioplastics. Available online: http://sorona.com/ (accessed on 28 March 2019).

39. Spitalsky, Z.; Tasis, D.; Papagelis, K.; Galiotis, C. Carbon nanotube-polymer composites: Chemistry, processing, mechanical and electrical properties. Prog. Polym. Sci. 2010, 35, 357-401. [CrossRef]

40. Otaegi, I.; Aramburu, N.; Müller, A.; Guerrica-Echevarría, G. Novel Biobased Polyamide 410/Polyamide 6/CNT Nanocomposites. Polymers (Basel) 2018, 10, 986. [CrossRef] [PubMed]

41. Dong, M.; Li, Q.; Liu, H.; Liu, C.; Wujcik, E.K.; Shao, Q.; Ding, T.; Mai, X.; Shen, C.; Guo, Z. Thermoplastic polyurethane-carbon black nanocomposite coating: Fabrication and solid particle erosion resistance. Polymer (Guildf) 2018, 158, 381-390. [CrossRef]

42. Ma, L.; Zhu, Y.; Wang, M.; Yang, X.; Song, G.; Huang, Y. Enhancing interfacial strength of epoxy resin composites via evolving hyperbranched amino-terminated POSS on carbon fiber surface. Compos. Sci. Technol. 2019, 170, 148-156. [CrossRef] 
43. Ma, L.; Li, N.; Wu, G.; Song, G.; Li, X.; Han, P.; Wang, G.; Huang, Y. Interfacial enhancement of carbon fiber composites by growing $\mathrm{TiO}_{2}$ nanowires onto amine-based functionalized carbon fiber surface in supercritical water. Appl. Surf. Sci. 2018, 433, 560-567. [CrossRef]

44. Wu, Z.; Cui, H.; Chen, L.; Jiang, D.; Weng, L.; Ma, Y.; Li, X.; Zhang, X.; Liu, H.; Wang, N.; et al. Interfacially reinforced unsaturated polyester carbon fiber composites with a vinyl ester-carbon nanotubes sizing agent. Compos. Sci. Technol. 2018, 164, 195-203. [CrossRef]

45. Zhang, J.; Zhang, Z.; Jiao, Y.; Yang, H.; Li, Y.; Zhang, J.; Gao, P. The graphene/lanthanum oxide nanocomposites as electrode materials of supercapacitors. J. Power Sources 2019, 419, 99-105. [CrossRef]

46. Liu, M.; Meng, Q.; Yang, Z.; Zhao, X.; Liu, T. Ultra-long-term cycling stability of an integrated carbon-sulfur membrane with dual shuttle-inhibiting layers of graphene "nets" and a porous carbon skin. Chem. Commun. 2018, 54, 5090-5093. [CrossRef]

47. Wang, Y.; Li, Z.; Wang, J.; Li, J.; Lin, Y. Graphene and graphene oxide: Biofunctionalization and applications in biotechnology. Trends Biotechnol. 2011, 29, 205-212. [CrossRef]

48. Rao, C.N.R.; Sood, A.K.; Subrahmanyam, K.S.; Govindaraj, A. Graphene: The New Two-Dimensional Nanomaterial. Angew. Chem. Int. Ed. 2009, 48, 7752-7777. [CrossRef]

49. Jang, B.Z.; Zhamu, A. Processing of nanographene platelets (NGPs) and NGP nanocomposites: A review. J. Mater. Sci. 2008, 43, 5092-5101. [CrossRef]

50. Novoselov, K.S.; Geim, A.K.; Morozov, S.V.; Jiang, D.; Zhang, Y.; Dubonos, S.V.; Grigorieva, I.V.; Firsov, A.A. Electric field effect in atomically thin carbon films. Science 2004, 306, 666-669. [CrossRef]

51. Kalaitzidou, K.; Fukushima, H.; Drzal, L.T. A new compounding method for exfoliated graphite-polypropylene nanocomposites with enhanced flexural properties and lower percolation threshold. Compos. Sci. Technol. 2007, 67, 2045-2051. [CrossRef]

52. Lee, C.; Wei, X.; Kysar, J.W.; Hone, J. Measurement of the elastic properties and intrinsic strength of monolayer graphene. Science 2008, 321, 385-388. [CrossRef]

53. Young, R.J.; Liu, M.; Kinloch, I.A.; Li, S.; Zhao, X.; Vallés, C.; Papageorgiou, D.G. The mechanics of reinforcement of polymers by graphene nanoplatelets. Compos. Sci. Technol. 2018, 154, 110-116. [CrossRef]

54. Liu, M.; Papageorgiou, D.G.; Li, S.; Lin, K.; Kinloch, I.A.; Young, R.J. Micromechanics of reinforcement of a graphene-based thermoplastic elastomer nanocomposite. Compos. Part A Appl. Sci. Manuf. 2018, 110, 84-92. [CrossRef]

55. Young, R.J.; Kinloch, I.A.; Gong, L.; Novoselov, K.S. The mechanics of graphene nanocomposites: A review. Compos. Sci. Technol. 2012, 72, 1459-1476. [CrossRef]

56. Marsden, A.J.; Papageorgiou, D.G.; Vallés, C.; Liscio, A.; Palermo, V.; Bissett, M.A.; Young, R.J.; Kinloch, I.A. Electrical percolation in graphene-polymer composites. 2D Mater. 2018, 5, 32003. [CrossRef]

57. Martino, L.; Guigo, N.; van Berkel, J.G.; Sbirrazzuoli, N. Influence of organically modified montmorillonite and sepiolite clays on the physical properties of bio-based poly(ethylene 2,5-furandicarboxylate). Compos. Part B Eng. 2017, 110, 96-105. [CrossRef]

58. Papageorgiou, D.G.; Kinloch, I.A.; Young, R.J. Graphene/elastomer nanocomposites. Carbon 2015, 95, 460-484. [CrossRef]

59. Codou, A.; Guigo, N.; van Berkel, J.G.; de Jong, E.; Sbirrazzuoli, N. Preparation and characterization of poly (ethylene 2,5-furandicarboxylate/nanocrystalline cellulose composites via solvent casting. J. Polym. Eng. 2017, 37, 869-878. [CrossRef]

60. Codou, A.; Guigo, N.; van Berkel, J.G.; De Jong, E.; Sbirrazzuoli, N. Preparation and crystallization behavior of poly (ethylene 2,5-furandicarboxylate)/cellulose composites by twin screw extrusion. Carbohydr. Polym. 2017, 174, 1026-1033. [CrossRef]

61. Matos, M.; Sousa, A.F.; Silva, N.H.C.S.; Freire, C.S.R.; Andrade, M.; Mendes, A.; Silvestre, A.J.D. Furanoate-based nanocomposites: A case study using poly(butylene 2,5-furanoate) and poly(butylene 2,5-furanoate)-co-(butylene diglycolate) and bacterial cellulose. Polymers (Basel) 2018, 10, 810. [CrossRef]

62. Paszkiewicz, S.; Janowska, I.; Pawlikowska, D.; Szymczyk, A.; Irska, I.; Lisiecki, S.; Stanik, R.; Gude, M.; Piesowicz, E. New functional nanocomposites based on poly(Trimethylene 2,5-furanoate) and few layer graphene prepared by in situ polymerization. Express Polym. Lett. 2018, 12, 530-542. [CrossRef]

63. Lotti, N.; Munari, A.; Gigli, M.; Gazzano, M.; Tsanaktsis, V.; Bikiaris, D.N.; Papageorgiou, G.Z. Thermal and structural response of in situ prepared biobased poly(ethylene 2,5-furan dicarboxylate) nanocomposites. Polymer (Guildf) 2016, 103, 288-298. [CrossRef] 
64. Tarani, E.; Papageorgiou, D.G.; Valles, C.; Wurm, A.; Terzopoulou, Z.; Bikiaris, D.N.; Schick, C.; Chrissafis, K.; Vourlias, G. Insights into crystallization and melting of high density polyethylene/graphene nanocomposites studied by fast scanning calorimetry. Polym. Test. 2018, 67, 349-358. [CrossRef]

65. Chieng, B.W.; Ibrahim, N.A.; Yunus, W.M.Z.W.; Hussein, M.Z. Poly(lactic acid)/poly(ethylene glycol) polymer nanocomposites: Effects of graphene nanoplatelets. Polymers (Basel) 2014, 6, 93-104. [CrossRef]

66. Ozawa, T. A New Method of Analyzing Thermogravimetric Data. Bull. Chem. Soc. Jpn. 1965, 38, 1881-1886. [CrossRef]

67. Budrugeac, P.; Segal, E.; Perez-Maqueda, L.A.; Criado, J.M. The use of the IKP method for evaluating the kinetic parameters and the conversion function of the thermal dehydrochlorination of PVC from non-isothermal data. Polym. Degrad. Stab. 2004, 84, 311-320. [CrossRef]

68. Vyazovkin, S. Modification of the integral isoconversional method to account for variation in the activation energy. J. Comput. Chem. 2001, 22, 178-183. [CrossRef]

69. Tsanaktsis, V.; Vouvoudi, E.; Papageorgiou, G.Z.; Papageorgiou, D.G.; Chrissafis, K.; Bikiaris, D.N. Thermal degradation kinetics and decomposition mechanism of polyesters based on 2,5-furandicarboxylic acid and low molecular weight aliphatic diols. J. Anal. Appl. Pyrolysis 2015, 112, 369-378. [CrossRef]

70. Buxbaum, B. The Degradation of Poly (ethylene terephthalate). Angew. Chem. Int. Ed. 1968, 7, $182-190$. [CrossRef]

71. Montaudo, G.; Puglisi, C.; Samperi, F. Primary thermal degradation mechanisms of PET and PBT. Polym. Degrad. Stab. 1993, 42, 13-28. [CrossRef]

72. Villain, F.; Coudane, J.; Vert, M. Thermal degradation of polyethylene terephthalate: Study of polymer stabilization. Polym. Degrad. Stab. 1995, 49, 393-397. [CrossRef]

73. Villain, F.; Coudane, J.; Vert, M. Thermal degradation of poly(ethylene terephthalate) and the estimation of volatile degradation products. Polym. Degrad. Stab. 1994, 43, 431-440. [CrossRef]

74. Konstantopoulou, M.; Terzopoulou, Z.; Nerantzaki, M.; Tsagkalias, J.; Achilias, D.S.; Bikiaris, D.N.; Exarhopoulos, S.; Papageorgiou, D.G.; Papageorgiou, G.Z. Poly(ethylene furanoate-co-ethylene terephthalate) biobased copolymers: Synthesis, thermal properties and cocrystallization behavior. Eur. Polym. J. 2017, 89, 349-366. [CrossRef]

75. Tarani, E.; Terzopoulou, Z.; Bikiaris, D.; Kyratsi, T.; Chrissafis, K.; Vourlias, G. Thermal conductivity and degradation behavior of HDPE/graphene nanocomposites. J. Therm. Anal. Calorim. 2017, 129, 1715-1726. [CrossRef]

76. Papageorgiou, D.G.; Terzopoulou, Z.; Fina, A.; Cuttica, F.; Papageorgiou, G.Z.; Bikiaris, D.N.; Chrissafis, K.; Young, R.J.; Kinloch, I.A. Enhanced thermal and fire retardancy properties of polypropylene reinforced with a hybrid graphene/glass-fibre filler. Compos. Sci. Technol. 2018, 156, 95-102. [CrossRef]

Sample Availability: Samples of the compounds are not available from the authors.

(C) 2019 by the authors. Licensee MDPI, Basel, Switzerland. This article is an open access article distributed under the terms and conditions of the Creative Commons Attribution (CC BY) license (http://creativecommons.org/licenses/by/4.0/). 